\title{
Geological Occurrence and Economic Feasibility in Closing Decisions by Gold Mines
}

\section{Stefano Mainardi}

\section{Department of Economics, University of Natal, Pietermaritzburg}

\begin{abstract}
With successful exploration of deposits often lagging behind mineral extraction, and the international price of gold showing no signs of recovery, mining companies are under pressure to reassess their strategies. The decision whether or not to close a mining activity is the outcome of a process of adapting expectations to a changing economic and geological environment. Part of the literature emphasizes the role of the mineral price and operating costs. However, the extent, pace and intertemporal allocation of metal recovery is in practice determined by a complex interaction of both these with other factors. Following a review of theoretical interpretations, and a reformulation of associated hypotheses, binary-response models are applied to a sample of gold mines in mainly three major southern hemisphere producers (Australia, South Africa and Chile).
\end{abstract}

JEL Q 32

\section{INTRODUCTION}

Gold production around the world may be facing a stagnating tendency by the end of the 1990s. Among major gold producers, South Africa and Australia are expected to have to deal with relatively more severe problems of potential closure of mines. Whereas in Australia this might be partly offset by the opening of new mines, many gold mining companies in both countries seem to increasingly rely on the opening and expansion of new mining operations outside their countries (Roskill, 1995: 109; Gooding, 1996). In South Africa, restructuring efforts by mining houses and technological innovations, along with enduring stable performance in the rand gold price, have so far prevented a continuous increase in the number of marginal gold mines.

The decision to shut down a mine may be either temporary or permanent. Except for particularly disruptive events which can almost permanently shorten the life of a mine, the latter case tends to occur when production is no longer 
economically attractive, in terms of price-cost relationship. In several cases, this process of depletion of the deposit does not coincide with a near-complete physical exhaustion, since the remaining ore does not justify additional investment, or the replacement of old investment capacity (Vogely, 1982: 251). However, this interpretation of the closing decision by mines should be refined in terms of different definitions of economic feasibility and geological availability of a mineral contained in a deposit. These definitions may include aspects such as market uncertainty, demand and price expectations, and technological improvements allowing a conversion of adjacent potentially exploitable mineral ores into reserves.

This study relies on recent information on open and closed mines located in major gold producer countries, particularly Australia, Chile and South Africa. The aim is an assessment of the role of economic and geological factors which may influence decisions to permanently or temporarily close down a mining operation. Without seeking to provide a comprehensive survey, the following section examines contributions to the theory of mine depletion, providing thereafter, a possible analytical framework of mine behaviour. Partly drawing on the theoretical background provided earlier, this analytical framework is tested with binary-choice (linear probability and logit) models. This is followed by concluding remarks in the last section.

\section{RESERVES, RESOURCES AND MINE PROFITABILITY}

A distinction among different concepts of geological availability is a necessary preliminary step to an analysis of the optimal development of a mine. In terms of categorisations such as those by McKelvey, Govett and Fettweis (Vogely, 1985; Govett-Govett, 1976: 18; Siebert, 1983: 33), reserves are defined as geologically identified, economically exploitable resources, i.e. that part of resources which (i) is known following sufficient geological evidence, and (ii) can economically be exploited for the extraction of a mineral commodity, at the time of determination, namely at present and in the near future.

According to a decreasing degree of geological assurance, one usually distinguishes among proven, probable and possible reserves (especially for petroleum), or, following a more recent terminology for most minerals, among measured, indicated and inferred reserves. The respective margins of errors for ore grade and tonnage of a mine deposit range from $10-20 \%$ for measured reserves, to possibly more than $30 \%$ (or $50 \%$ for some authors) for inferred reserves. In practice, reserve estimates reported by mining companies refer to 'demonstrated', i.e. measured and indicated, reserves, excluding inferred reserves. Moreover, in some cases only the recoverable share of these reserves is 
accounted for, to allow for material lost with extraction ${ }^{2}$. Another reason for some underreporting by mining companies may be due to tax purposes, with the indication of a 'minimum quantity' of remaining ore which would still ensure investors about a sufficient time horizon and justify exploration outlays.

A broader concept of mineral availability is represented by resources, which include currently (reserves) and potentially exploitable mineral ores. Nonreserve resources represent a target for future evaluation. They can be below current levels of economic feasibility (sub-economic, thus implying the need for future mineral price increases or equivalent technological advances), and/or geologically known with less confidence (hypothetical and speculative). In the early theoretical contributions on the choice of the rate of extraction by a mine, non-reserve resources are ignored, and the analysis assumes all reserves as known.

Hotelling's seminal article hypothesises certainty of information and Ricardian conditions of increasing extraction costs, with cumulative deterioration in terms of grade and quality of the ore. Uncertainty is marginally treated, with reference to exploration activity and the associated need for public intervention (Hotelling, 1931; Devarajan-Fischer, 1981: 69-70). Later authors have built upon Hotelling's model by formulating more articulated hypotheses. Ore characteristics such as ground solidity, extent of impurities, mineral composition and hardness, which contribute to define the quality of the ore, or aspects affecting the workability of the ore (such as the thickness of the seam) may offset the percent metal content (ore grade), or may themselves have contradictory effects. Furthermore, adjustments to lower grades of the ore, eventually coupled with higher rates of output, often tend to lag behind price rises to a greater extent than in the reverse adjustment process (to price declines) (Carlisle, 1954: 602-3; 616; Herfindahl, 1967; Scott, 1967; Brobst, 1993). Therefore, the relationships between grade and quality of the ore, cost of recovery and mineral price are more complex than what initially hypothesised.

Carlisle (1954) considers both the rate of recovery, i.e. the number of tonnes mined per unit of time, and the level of recovery, i.e. the selection of a final target percentage amount of mineral extracted from the soil (Table 1: cases 1 and 2). For deposits characterised by wide veins of uniform quality, or in the presence of reasonable knowledge of the geological occurrence, the cut-off grade $^{3}$ can be established at the beginning of the mining operation. The planning decision will then only concern the rate of recovery (case 1), such as to allow a maximisation of profits over the entire life time of the mine, corresponding to the minimum average total unit cost. An intermediate situation, closer to standard microeconomic profit maximisation, i.e. with equilibrium somewhere between this point and maximum annual profit, would arise when high 
discounting is used. In the latter case, economies of speed (or, analogously, long-term market risks) and economies of scale are particularly relevant, with a consequent reduction of the mine life.

If the level of recovery is allowed to change while keeping the rate constant, to some extent the opposite framework can be envisaged. A low cut-off grade would lead to high levels of recovery, with annual production fixed at maximum annual profit equilibrium. High discounting will favour a solution closer to the least-cost level, with selective mining and a likely further shortening of the life of the mine (case 2: a). The more negative the market expectations, the more the mining company will be tempted to recover only the rich ore, thus ultimately depriving itself of the scope for greater exploration and development of the deposit. Equilibrium is found in a series of static solutions, with the build up of capacity at lower levels than in the case of optimistic expectations.

A joint solution is in practice likely to be based on comparing alternative levels of recovery each at its optimum rate, in view of the uncertainty surrounding the ore body (as opposed to, e.g., estimated costs for specific sections of the deposit) (Carlisle, 1954: 607). In the short run, physical and financial restrictions may cause downward adjustments in the rate of extraction to higher levels of recovery (as reflected by declining ore grades). This entails a possible reverse relationship between levels and rates, although this is not necessarily the case in the long run (case 2: b). This interpretation rests on the hypothesis that the level of recovery is an inverse function of the cut-off grade, unless the 'homogeneous grade' conditions are present. In the latter case, typical of fluid reserves such as oil fields, the quantity of recoverable mineral would be a function of increasing (pumping) costs, but at a constant average ore grade (Scott, 1967: 27-8).

This theoretical framework has more recently been refined in various respects. Firstly, 'Lasky's rule' of an inverse relationship between average ore grades and cumulative ore tonnages (produced in the past and estimated reserves) does not seem to hold for all types of deposits and minerals. For scarce elements, such as gold and silver, a bimodal (or multimodal) distribution has been suggested, with the mineralogical threshold ${ }^{4}$ possibly lying between the humps of the bimodal curve (Scott, 1967: 25; Brobst, 1993: 593-4). This implies possible discontinuities or kinks along the downward-sloping curve relating the average ore grade to the quantity of recoverable mineral.

Secondly, factors other than the ore grade and the discount rate influence the choice of the rate of recovery. These factors, which favour a tilt in the production sequence skewed towards the early periods of a mine life, include cumulative deterioration of mining conditions and negative expectations on demand-supply conditions ${ }^{5}$ (Scott, 1967). Regarding the former, even in the 
presence of a homogeneous grade, deposit, eventually subsequent to an initial development phase an increasing distance of the ores from the shaft and mill tends to raise average costs of extraction. This also inevitably slows down the process of depletion. With no a priori geological knowledge of the deposit, the effects on the life of the mine are uncertain (Table 1: case 3). On the one hand, some reserves may be later found not to be ore, or reconverted to sub-economic resources due to, e.g., substantial energy cost increases. On the other hand, the mine life could be lengthened by the extraction of ores previously thought to be too remote or low-grade.

Thirdly, if ores of different grade and quality are highly intermixed, with little scope for selective mining, optimum rates and levels of recovery can be difficult to establish. Net effects will lie somewhere between conditions of uniformity and occurrences with relatively easier selection of seams of different grade/quality (Table 1: case 4). The blending of ores of different grades may be favoured by economies of mine and mill operation, due to the contiguity of the respective sites. This and the above points should ideally be incorporated in a model on closing decisions by mines. While some of the issues can be assessed only with a detailed analysis focused on individual mines, a cross-mine study can still provide some insights.

\section{HYPOTHESES AND ECONOMETRIC ESTIMATES}

\section{Optimum extraction paths and shutdown decisions}

The brief review in the preceding section has highlighted determinants of mine planning in an increasingly complex and uncertain geological environment. in order to account for possible future extensions of the life of a mine, compared to its initially anticipated geological and economic constraints, an optimum path of extraction can be illustrated by the following constrained maximisation conditions:

$\max \left[\max \int_{0}^{\pi}(\mathrm{p}(\mathrm{t}) \mathrm{s}(\mathrm{t})-\mathrm{c}(\mathrm{s}(\mathrm{t}), \mathrm{t}, \mathrm{r})) \mathrm{D}(\mathrm{t}) \mathrm{dt}, \max \mathrm{E}\left(\int_{10}^{t}(\mathrm{p}(\mathrm{t}) \mathrm{s}(\mathrm{t})-\mathrm{c}(\mathrm{t})) \mathrm{D}(\mathrm{t}) \mathrm{dt} / \mathrm{S}_{0}<\right.\right.$ $\left.\left.\int_{0}^{t} \mathrm{~s}(\mathrm{t}) \mathrm{dt} \leq \mathrm{S}_{\mathrm{T}}\right)\right]$

subject to $\int_{0} s(t) d t \leq S_{0}$.

The mine maximises the discounted profit per tonne extracted $(D(t)$ is the discount factor). The mineral price $(p)$ and the rate of extraction $(s)$ are both a function of time. Besides also being dependent on time, the extraction cost per unit of time (c) can be assumed to be an increasing function of the recovery rate 
and the cumulative deterioration of the mine, i.e. strictly convex in $s$ and $r$, respectively. Abstracting from initial economies of speed, this assumption can be made if there is complete prior knowledge of the geological features of the deposit, and if one excludes case 4 (Table 1). The solution would then be exclusively based on the first option in the objective function. This option foresees an exhaustion of the deposit by time $T$, with no possibility of enlargement of initially estimated recoverable reserves $\left(S_{t}\right)$. The difference between price and marginal cost at time $t$ would represent the opportunity cost of using the limited resource at that time rather than at an alternative time (Scott 1967: 35-6; Sweeney 1993: 192-3).

An alternative solution is represented by the right-hand side of the objective function. If by time $T$ the reserves have been increased $\left(S_{7}\right)$ compared to the initial estimate (possibly by even including high-grade or high-quality ore sites), the depletion of the mine can theoretically be postponed to an indefinite period, with no unique solution in terms of an 'optimal' extraction path (unless a priori information on the probability distribution of the stochastic elements is assumed, with the possible application of Bayesian or other stochastic programming techniques) (Rao 1984: ch. 11; Sengupta 1982: 24-34). The optimisation problem would therefore involve a maximisation of the discounted unit profit for known reserves, or of the expected value of its conditional term, given a future expected expansion of the orebody, whichever is the higher.

Related to this framework, the following hypotheses can be formulated:

a) At levels of profitability below optimum, or even more so in cases of economic loss, the mining company may still prefer to continue operations for some time, instead of closing down, if anticipated conditions are favourable. In economic and geological terms, this is likely to occur whenever (i) the life expectancy of the mine's demonstrated reserves, given current and projected growth rates of annual mineral production, is not approaching economic exhaustion, and (ii) there is a relatively large scope for a progressive expansion of demonstrated reserves (due to, e.g., expected technological advances or mineral price developments).

b) At similar conditions of economic feasibility and geological occurrence, which would eventually justify a temporary shutdown of a mine, underground mines will be less 'flexible' than open-pit mining operations. This would be revealed by either attempts to prolong the life of the mine, or the opposite decision to permanently close the mine. Following a temporary closing, changed economic circumstances may allow resumption of operations provided that the costs of rehabilitating the mine 
are amortised. This can be especially difficult for underground mines (Brobst, 1993: 583).

\section{Sample and empirical results}

To test the above hypotheses, dichotomous choice models are here applied to a cross-section sample of 153 gold-producing mines. This sample, which includes operating and recently closed mines, was obtained from the RMG computerised database of mines world-wide (Raw Materials Data, June 1997 update, compiled by Raw Materials Group-Stockholm). The criteria for the construction of the sample were the availability and coherence of information for the variables defined below ${ }^{6}$.

Three relevant producing countries in the southern hemisphere, namely Australia, Chile and South Africa, are well represented. The number of their mines with sufficient information is substantial and covers almost the entire sample (138). In 1996, these economies represented respectively $12.3 \%, 2.4 \%$, and $21 \%$ of world gold production, thus occupying the third, tenth, and first position among gold producing countries. The remaining 15 mines of the sample are selected cases of mines located in other major producing countries. For three of these countries, only few mines provide the needed information (Namibia, Papua New Guinea -henceforth PNG-, the Philippines), while for other two (Canada and the United States) a thorough coverage would have required additional data collection efforts, and would have biased results towards another world region (with greater risk of including pollution-related 'premature' shutdowns of mines: Salant, 1995: 97).

Relative to the three countries examined here with greater attention, part of the geological information on the mines can be compared with estimates for mine projects at an early stage, also provided by the RMG database. Resources and, to a lesser extent, their estimated average ore grades appear to be asymmetrically distributed across mines, especially for those under construction, with few large mines pulling average figures above the corresponding median values (Table 2 ). Recent exploration efforts seem to have identified new deposits (currently under feasibility study) which are potentially less endowed than older ones, according to the extension and percent metal content of resources.

An apparent high variation among resource estimates of recently or forthcoming closed mines is indicated by a relatively higher coefficient of variation $(320.2$, for sixteen mines). However, this is spuriously due to the influence of two far outliers, represented by a South African and an Australian mine which have been closed (in a provisory and permanent way, respectively), despite substantial resources (but see note 7 for one of these mines). This leads to a gap 
between an average of $13.2 \mathrm{Mt}$ and a median of $0.8 \mathrm{Mt}$, for this sub-sample. If these mines are excluded from the sub-sample, a clear drop in the average value of resources is registered, although with no remarkable differences from open mines in terms of the ore grade (Table 2). Measures of level and spread of the cross-mine distribution are not substantially altered for open mines if the whole sample is considered. Once again, the presence of another far outlier, represented by the large abandoned Bougainville gold-copper mine in PNG, further widens the gap between average and median values as far as resources of all closed mines of the sample are concerned.

Binary choice models have been applied to dummies identifying mines which are temporarily (variable status l) or permanently (status2) closed. The latter group includes also a few mines for which, in the survey information year (1994-96, depending on the mine), permanent closure is anticipated by the year 1999 at the latest ${ }^{7}$. To capture the features expressed by the hypothesis $a$ above, the ratio of annual ore production to demonstrated reserves and the ratio of the latter variable to total estimated resources of the mine deposit are used, reflecting points (i) and (ii) under $a$ (section 3.1 ), respectively (oreqrprat and rprrat: Table 3). These ratios are calculated by first multiplying the gross ores (in $\mathrm{Mt}$, estimated, for reserves and resources, or milled for output) by the respective ore grades (grams per tonne), thus obtaining figures for these variables in thousands of tonnes of fine gold ${ }^{8}$.

Independently from the economic profitability, one can expect that the coexistence of very high values in these ratios (close or equal to one for rprrat, and above, say, 0.5 for oreqprrat) ${ }^{9}$ will indicate the proximity of physical exhaustion for a mine deposit. Economic profitability is in turn proxied by the ratio of the $\mathrm{LME}$ gold price to the average operating cost per troy oz of fine gold produced (gpcorat: Table 3). Since both variables were originally given in US dollars or local currency relative to the information year, the period average exchange rates of the Australian dollar and the South African rand were used for conversion purposes when needed (IMF 1997). Finally, dummies are introduced in the models to account for the hypothesis b above (variables typel and type2, since some mines are partly underground, partly open-pit: Table 3), and the possible 'buffering' influence of co-product metal output extracted from polymetallic deposits (such as gold-silver-copper, or other basic metals) (categ: Table 3).

Regressions for temporary shutdowns (status l) yield statistically insignificant results in terms of overall explanatory power and individual parameters (except, to a limited extent, for the ratio of ore production to demonstrated reserves, which exercises a similar influence as for permanently closed mines). Relative to the variable status 2 , OLS and maximum likelihood estimates, for the linear 
probability and the logit models respectively, are reported in Table 3. Due to several missing values (especially relative to operating costs of the mines), regressions are based on 90 or 47 observations, depending on whether the proxy for economic profitability is included. The presence of one of the outliers mentioned above, namely an Australian mine (the other two cases do not enter the regressions, since no full information is available), only marginally affects the stability of individual parameters in the linear regression. By contrast, logit results differ to a greater extent if this case is excluded from the relatively larger sub-sample (Table 3: lit 3 and lit4; see note 7).

As usually found for these models, the logit model appears to be superior in terms of goodness of fit, if the Nagelkerke R-square is used as an indicator approximately comparable to the $\mathrm{R}$-square in standard OLS regressions (Nagelkerke, 1991; Norusis, 1997: 48; Maddala, 1986: 39-40 and Cox-Snell, 1987: 209). The relatively large proportion of unexplained variation in $l p l$ (Table 3) is not reduced by accounting for possible non-linearities: terms in the square of non-categorical variables, eventually added to the regression equation, turn out to have statistically insignificant parameters. For the logit estimation, the Hosmer and Lemeshow goodness-of-fit test fails to reject the null hypothesis of no difference between observed and predicted values for equations lit l, lit 3 and lit4 (lit2 is likely to have too few observations for this test: HosmerLemeshow, 1989: 140-5). This indirectly indicates a satisfactory matching of observed and predicted frequencies. However, in terms of predictions on individual observations, and based on a 0.5 cut value, the logit model appears to be better suited to predict the choice of remaining open (above $95 \%$ ), than the alternative of closing down ( $50 \%$ of correct prediction for litl, nearly $67 \%$ for lit 2 -also without dummies-, and $56 \%$ for lit 3 and lit 4$)^{10}$.

Limited to the three percentage variables, estimated parameters in both models have the expected signs. Among these variables, however, gpcorat is not statistically significant, contrary to expectations. As far as categorical variables are concerned, contradictory results are given by the two models about the possible role of co-product metals. Only equations litl, lit 3 and lit 4 show the expected sign in the estimated parameter, implying a reduced probability of closing. An absence of unequivocal indications and statistical significance is similarly present for the dummies on the type of deposit. A likelihood-ratio test would give preference to a restricted version of the model, without these dummies (Table 3: lit4; Mukherjee et al., 1998: 325)". This result may at least partly be explained by the opposite effects hypothesised in the previous section. Ceteris paribus, underground mines may have a wider variety of responses to changing geological and economic circumstances than other mines. This is supported by a scatter plot of typel versus logit residuals in equation lit $3^{12}$. 
Particularly relevant appears to be the influence of the share of annual production in proven and probable reserves. According to the linear probability model (equations $l p l$ and $l p 2$ ), a $10 \%$ increase in this share would bring about on average 0.045 added probability of a closing decision (with certainty equal to 1). Following both models, the scope for increased potential geological availability, as proxied by rprrat, is found to have a relatively lesser impact on postponing closing decisions. A limited comparison of logit parameter estimates with those of the linear probability model is possible for noncategorical explanatory variables, through a suitable transformation ${ }^{13}$. In the logit model the change in probability is a function of the probability itself. Moreover, as supposed to be often realistic, the model presupposes a higher sensitivity of the dependent variable to changing conditions in the middle range of the distribution (Pindyck-Rubinfeld, 1986: 287-300). In the above example, relative to results of equation lit $l$, the added probability of a closing decision to a $10 \%$ increase in oreqprrat would range from 0.09 at $\mathrm{p}_{\mathrm{i}}$ equal to 0.5 , to 0.03 towards the 'wings' $\left(p_{i}=0.1\right.$ or 0.9$)$.

Whereas the dynamic impact, that is relative to probability changes, is to some extent comparable between the two models, the static effects vary substantially. If one considers, for instance, equations $l p l$ and litl, the probabilities of permanently closing for underground mines characterised by (i) gold as an individual product, (ii) no sub-economic or inferred/undiscovered resources (rprrat $=1$ ), and (iii) latest annual output of fine gold amounting to $50 \%$ or $90 \%$ of reserves, would be 0.28 and 0.46 for the linear probability model (with oreqrprat $=0.5$ and 0.9 , respectively). Conversely, the logit parameters would approximately double these probabilities $(0.61$ and 0.87$)$. For the parsimonious regression equation lit 4 , which does not distinguish between underground and open-pit mining (while apparently having the same predictive power as lit 3 ), the respective probabilities would be even higher $(0.7$ and 0.93$)$. The linear probability model, also if the outlier is accounted for, appears to systematically under-predict probabilities of permanent closure ${ }^{14}$.

\section{CONCLUSION}

Decisions concerning the rate and level of recovery, and ultimately the time of abandonment or temporary interruption of mining operations, are associated with indicators of economic health and geological features of a deposit. Early theoretical contributions have tended to emphasise the price-cost relationship. They assume prior knowledge of geological and economic conditions and a smooth negative schedule relating the average ore grade to the quantity of recoverable mineral. Other authors have proposed a more articulated framework, which accounts for various geological environments and degrees of information. 
In this study, the choice of the optimum extraction path for a mine is hypothesised to have no unique solution, and to depend on the possibility of later recovery of a mineral out of initially sub-economic, undiscovered or inferred resources.

The empirical analysis has focused on gold mines, with particular attention to those located in Australia, South Africa and Chile. Permanent closures of these mines are found to be strongly influenced by their 'life expectancy' and the scope for expansion of existing reserves. The current economic profitability and type of deposit seem to be less relevant factors. The analysis could be deepened into aspects of geological availability and economic feasibility other than those considered here. This would require a study focused on individual mines, with information on, among others, spatial distribution of the deposit, taxation treatment, capital outlays, and market expectations.

The situation is particularly delicate for South African mines. They are much older $^{15}$ and generally reaching high depth levels underground, in contrast with a prevalence of open-pit mining elsewhere. Opinions on medium-term prospects of the South African gold mining industry vary from warnings of near inevitable downsizing and closing of loss-making mines to arguments stressing a renewed profitability and ore grade flexibility. One should hope that, besides the euphoria on new mining ventures in emerging producer countries, such as in West Africa, efforts are undertaken to contain the social costs of this restructuring. 
Table 1 - Mine development and exhaustion under different conditions; literature hypotheses

\begin{tabular}{|c|c|c|c|c|}
\hline $\begin{array}{l}\text { characteristics of the } \\
\text { deposit }\end{array}$ & $\begin{array}{l}\text { a. optimum } \\
\text { rate of } \\
\text { recovery }\end{array}$ & $\begin{array}{l}\text { b. optimum level of } \\
\text { recovery }\end{array}$ & $\begin{array}{l}\text { effects on life } \\
\text { of the mine * }\end{array}$ & underlying factors \\
\hline $\begin{array}{l}1 \text { uniform quality and } \\
\text { accessibility, and/or } \\
\text { prior knowledge of } \\
\text { geological occurrence }\end{array}$ & $Q_{\text {NPV }}$ & $\begin{array}{l}\text { constant (no } \Delta \text { cut-off } \\
\text { grade) }\end{array}$ & $\downarrow$ & $\begin{array}{l}\text { economies of speed vs. } \\
\text { diseconomies of scale }\end{array}$ \\
\hline $\begin{array}{l}2 \text { declining grade and } \\
\text { quality and/or } \\
\text { workability of the ore }\end{array}$ & $\begin{array}{l}\text { a. constant } \\
\text { b. decreasing }\end{array}$ & $\begin{array}{l}\mathrm{nQ} \\
\uparrow \mathrm{d} \rightarrow \mathrm{m} \mathrm{Q}_{\mathrm{NPV}} \\
\text { increasing }\end{array}$ & $\downarrow \downarrow$ & $\begin{array}{l}\text { market uncertainty } \\
\text { (with limit to attainment of } \\
\text { economies of scale) } \\
\text { diminishing returns }\end{array}$ \\
\hline $\begin{array}{l}3 \text { remoteness of the ore } \\
\text { from shaft/mill, with } \\
\text { - prior knowledge } \\
\text { - uncertainty }\end{array}$ & $\begin{array}{l}\text { decreasing } \\
\text { and tilted }\end{array}$ & $\begin{array}{l}\text { constant } \\
\text { (homogeneous grade) } \\
?\end{array}$ & $\uparrow$ & $\begin{array}{l}\text { cumulative deterioration } \\
\text { (with geological uncertainty) }\end{array}$ \\
\hline $\begin{array}{l}4 \text { intermixed ores of } \\
\text { different grades/sites }\end{array}$ & $?(1$ or 2$)$ & $?(1$ or 2$)$ & & $\begin{array}{l}\text { economies of mine and mill } \\
\text { operation }\end{array}$ \\
\hline
\end{tabular}

* relative to conditions outlined in the first row (maximum level of recovery: $n Q$ )

** selective mining

$\mathrm{n}, \mathrm{m}$ mine life

Q maximum profit per period

QNPV maximum discounted profit per tonne extracted $(d=$ discount factor) 
Table 2 - Resources: descriptive statistics for gold mines at different stages (Australia, Chile, South Africa; information years: 1994-96)

\begin{tabular}{|l|c|c|c|c|c|c|c|c|}
\hline stage & \multicolumn{2}{|c|}{ feasibility (28) } & \multicolumn{2}{|c|}{ construction (31) } & \multicolumn{2}{|c|}{ operating $\left(\mathbf{1 0 1}^{\star}\right)$} & \multicolumn{2}{c|}{ closed (14^)} \\
\hline variable & resources & grade & resources & grade & resources & grade & resources & grade \\
\hline average & 9.0 & 3.1 & 41.3 & 4.5 & 28.2 & 4.1 & 0.9 & 4.4 \\
\hline median & 1.8 & 2.1 & 2.3 & 3.1 & 7.8 & 3.0 & 0.7 & 3.1 \\
\hline $\begin{array}{l}\text { lower } \\
\text { quartile }\end{array}$ & 0.6 & 1.6 & 0.2 & 1.9 & 2.7 & 1.8 & 0.2 & 2.0 \\
\hline $\begin{array}{l}\text { upper } \\
\text { quartile }\end{array}$ & 4.0 & 3.6 & 32.0 & 5.8 & 26.2 & 5.3 & 1.1 & 6.3 \\
\hline $\begin{array}{l}\text { Coefficient } \\
\text { of variation }\end{array}$ & 250.0 & 83.3 & 205.8 & 93.0 & 197.8 & 87.6 & 99.7 & 68.2 \\
\hline
\end{tabular}

In parentheses: number of mines (* including Navachab mine, Namibia; ${ }^{\wedge}$ permanently or temporarily closed, and excluding an Australian and a South African mine: see text); resources in Mt of ore; grade in grams/tonne of ore; coefficient of variation: (s.d./mean) 100 
Table 3 Closing decisions by gold mines: linear probability and logit estimates

\begin{tabular}{|c|c|c|c|c|c|c|c|c|c|c|c|c|}
\hline \multicolumn{3}{|c|}{ linear probability model } & \multicolumn{5}{|c|}{ logit model } & \multirow[b]{2}{*}{ Wald } & \multirow[b]{2}{*}{$\begin{array}{l}\text { coeff. } \\
\text { (lit3) }\end{array}$} & \multirow[b]{2}{*}{ Wald } & \multirow[b]{2}{*}{$\begin{array}{l}\text { coeff. } \\
\text { (lit4) }\end{array}$} & \multirow[b]{2}{*}{ Wald } \\
\hline $\begin{array}{l}\text { dependent: } \\
\text { status2 }\end{array}$ & $\begin{array}{l}\text { coeff. } \\
\text { (|pl) }\end{array}$ & t stat. & $\begin{array}{l}\text { coeff. } \\
\text { (lp2) }\end{array}$ & t stat. & $\begin{array}{l}\text { coeff. } \\
\text { (litl) }\end{array}$ & Wald & $\begin{array}{l}\text { coeff. } \\
\text { (lit2) }\end{array}$ & & & & & \\
\hline constant & -0.14 & -2.13 & -0.01 & $-0.07^{\wedge}$ & -3.00 & 3.98 & -13.9 & $0.01^{\wedge}$ & 3.58 & 4.19 & -4.30 & 7.91 \\
\hline rprat & 0.17 & 1.91 & 0.28 & 2.16 & 1.57 & $1.25^{\wedge}$ & 3.63 & $1.59^{\wedge}$ & 2.42 & $2.06^{\wedge}$ & 2.91 & $3.02^{\prime}$ \\
\hline oreqrprat & $0 . \overline{45}$ & 7.11 & 0.45 & 6.45 & 3.62 & 9.48 & 4.77 & $3 . \overline{83}$ & 4.34 & 8.77 & 4.44 & 9.90 \\
\hline gpcorat & & & -1.11 & $-1.11^{\wedge}$ & & & -1.50 & $0.43^{\wedge}$ & & & & \\
\hline categ & 0.15 & $1.66^{\circ}$ & 0.09 & $0.51^{\wedge}$ & -1.82 & 2.86 & 7.46 & $0.004^{\wedge}$ & -2.32 & 3.75 & -2.28 & 3.87 \\
\hline typel & 0.09 & $1.12^{\wedge}$ & -0.03 & $-0.24^{\wedge}$ & -7.59 & $0.04^{\wedge}$ & -4.83 & $0.01^{\wedge}$ & -7.36 & $0.04^{\wedge}$ & & \\
\hline type2 & -0.06 & $-0.84^{\wedge}$ & -0.04 & $-0.42^{\wedge}$ & 7.65 & $0.04^{\wedge}$ & 7.37 & $0.02^{\wedge}$ & 7.16 & $0.04^{\wedge}$ & & \\
\hline $\begin{array}{l}\mathrm{R}^{2}(\mathrm{adj}) \\
\mathrm{R}^{2}(\mathrm{~N}) \\
\mathrm{F} \\
\chi^{2} \\
\chi^{2}(\mathrm{HL})\end{array}$ & 0.37 & & 0.50 & & $\begin{array}{r}0.52 \\
27.5(5) \\
7.1^{\wedge}(8)\end{array}$ & & $\begin{array}{r}0.70 \\
21.8(6) \\
17.9(7)\end{array}$ & & $\begin{array}{r}0.63 \\
31.8(5) \\
3.8^{\wedge}(8)\end{array}$ & & $\begin{array}{r}0.60 \\
30.3(3) \\
5.7^{\wedge}(8)\end{array}$ & $1.5(2)^{\wedge}$ \\
\hline $\mathrm{N}$ & 90 & & 47 & & 90 & & 47 & & 89 & & 89 & \\
\hline
\end{tabular}

$\wedge$ less than $90 \%$ confidence interval; " $90 \%$ confidence interval (in all other cases: $95 \%$ confidence interval or more; for Wald statistic, see note 11); N: sample size (in lit3 and lit4, outlier excluded: see text and note 7); $\mathbf{R}_{(\mathrm{N})}^{2}$ : Nagelkerke $R^{2}, \chi^{2}$ : chi-square test on exclusion restrictions for parameters other than the constant term (in the

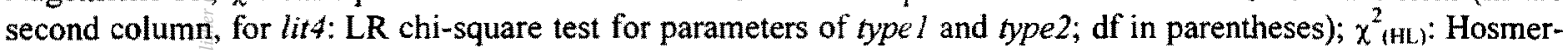
Lemeshow chi-square test ( $\mathrm{d} f$ in parentheses)

Variables

status2 (1 if mine is permanently closed, or expected to be so by 1998-99; 0 otherwise); rprrat (demonstrated reserves/resources, in kt of fine gold); oreqrprat (ore production for last or latest year/demonstrated reserves, in kt of fine gold); gpcorat (gold price/average operating costs, in USD or local currency/troy oz, for last or latest year); categ ( 1 if polymetallic mine deposit, 0 otherwise); typel ( 1 if underground mine, 0 otherwise); type 2 ( 1 if underground and 'mixed', 0 if open-pit) 


\section{ENDNOTES}

1 Useful discussions with J. Apaloo, and financial support from the University of Natal/URF, are gratefully acknowledged. The usual caveat applies.

2 The recovery ratio, i,e. the percentage share of recoverable over total reserves, is estimated to amount to up to $90 \%$ for several metals.

Cut-off grade is defined as the lowest grade possible for some defined time period, so as to extract a mineral economically from a deposit (e.g., $0.1 \%$ copper from porphyry ore, or $0.01 \%$ for by-product cobalt), when blended with higher grade ore (Brobst, 1993: 587).

The mineralogical threshold may or may not coincide with the economic threshold represented by the cut-off grade, depending on mineral and time reference. It refers to the minimum natural conditions allowing the formation of separate particles of minerals, which, if sufficiently abundant, could be commercially exploited (Brobst, 1993: 588).

Unlike Carlisle, negative market expectations both reduce, and tilt towards the present the rates of extraction over a mine project life (Scott, 1967: 46-50).

6 Since some of the variables used in the regressions have missing values for a large number of observations, the econometric estimates concem only parts of this sample (Table 3 ).

An Australian mine, which was temporarily shut down after being flooded by a cyclone, and reopened in April 1996 (the information year for that mine), is classified as operating. For temporary closures, the definition in the RMG database is strictly adhered to, with temporary mines being only those which are registered as such at the time in which the information is provided (1994-1996). It should be noticed that the Australian outlier case (Tables 2 and 3 ) is represented by an officially permanently closed mine according to RMG 1995 information. However, this mine has actually been reactivated, along with other two adjacent mines, under a new name (I wish to thank A. Riganti and B. Groenewald of the Geological Service of Western Australia for this note).

The use of gross ores would have biased the results, since for most mines there are substantial disparities among average ore grades of the three variables (resources, demonstrated reserves, and production).

A value higher than 1 is not to be excluded for the variable oreqprrat (in fact it turns out to be the case for six mines). Abstracting from the slowdown effects of cumulative deterioration in mining, this would theoretically point at a potential remaining life expectancy for a mine of less than one year.

10 The incorrectly predicted cases tend to be not explainable by the model, given the general clustering of estimated probabilities at both ends of the 
frequency histograms. This problem is alleviated, but not removed, if the outlier case is not included in the regressions. However, in reality all such cases, identified by large standardised estimated residuals, can be considered atypical. For the outlier, see note 7 . The remaining observations concern a few mines which are foreseen to close by 1999 , while not actually being permanently closed in the information year. In this case, the respective Wald statistics may already be indicative. However, one should bear in mind that the Wald statistic tends to be biased against the rejection of the zero null hypothesis when regression coefficients have large absolute values (Norusis, 1997: 5 and HauckDonner, 1977).

Although in logit regression the dependent variable is the logarithm of the odds of an event's occurring, the residuals, as in the linear probability model, are the difference between the observed and predicted probabilities of the events, with the latter based on the model. The logit residuals are the residuals transformed in logit scale, that is divided by estimates of their variances $\left(p_{i}\left(1-p_{i}\right)\right)$.

Indicating with $p_{i}$ a probability and $\beta_{j}$ a logit parameter for a continuous variable, the change in probability can be approximated as: $\Delta p_{i} \equiv \beta_{j}\left(p_{i}\right.$ $\left(1-p_{i}\right)$ ) (Pindyck-Rubinfeld, 1986: 299).

Moreover, in the presence heteroscedasticity, as intrinsic to the linear probability model, estimated coefficients are inefficient, although unbiased. However, the weighted least-squares procedure does not yield efficient estimates for small samples and is sensitive to errors of specification (Pindyk-Rubinfeld, 1986: 276).

is In the sample, the average life of mines which are closed or for which a specific year of closure is foreseen (including the expected life of mines anticipated to close before the year 2020), is 54 years in South Africa. By contrast, the respective average figure barely exceeds 6 years in Australia, Chile and the other countries of the sample.

\section{REFERENCES}

1. BROBST, D.A. (1993) "Fundamental Concepts for the Analysis of Resource Availability", in G. Heal (Ed.), The Economics of Exhaustible Resources, E. Elgar, Aldershot: 575-611.

2. CARLISLE, D. (1954) "The Economics of a Fund Resource with Particular Reference to Mining", The American Economic Review, 44: 595-616.

3. COX, D.R. \& SNELL, E.J. (1987) Analysis of Binary Data, Chapman and Hall, London. 
4. DEVARAJAN, S. \& FISHER, A.C. (1981) "Hotelling's 'Economics of Exhautible Resources': Fifty Years Later", Journal of Economic Literature, 19(1): 65-73.

5. GOODING, K. (1996) "Declining Capacity to Hit Gold Production", Sunday Times (Business Times), May 19:2.

6. GOVETT, G.J.S. \& GOVETT, M.H. (Eds.) (1976) World Mineral Supply. Assessment and Perspective, Elsevier, Amsterdam.

7. INTERNATIONAL MONETARY FUND (IMF) (1997) International Financial Statistics Yearbook 1997, Washington DC.

8. HAUCK, W.W. \& DONNER, A. (1977) "Wald Test as Applied to Hypotheses in Logit Analysis", Journal of the American Statistical Association, 72(360): 851-3.

9. HERFINDAHL, O.C. (1967) "Depletion and Economic Theory", in M. Godfrey (Ed.), Extractive Resources and Taxation, University of Wisconsin Press, Madison: 63-89.

10. HOSMER, D.W. \& LEMESHOW, S. (1989) Applied Logistic Regression, J. Wiley \& Sons, New York.

11. HOTELLING, H. (1931) "The Economics of Exhaustible Resources", Journal of Political Economy, 39(2): 137-75.

12. MADDALA, G.S. (1986) Limited Dependent and Qualitative Variables in Econometrics, Cambridge University Press.

13. MUKHERJEE, C., WHITE, H. and WUYTS, M. (1998) Econometrics and Data Analysis for Developing Countries, Routledge, London.

14. NAGELKERKE, N.J.D. (1991) "A Note on a General Definition of the Coefficient of Determination", Biometrika, 78(3): 691-2.

15. NORUSIS, M.J. (1997) SPSS Professional Statistics 7.5, SPSS Inc., Chicago.

16. PINDYCK, R.S. \& RUBINFELD, D.L. (1986) Econometric Models and Economic Forecasts, McGraw-Hill, Singapore.

17. RAO, S.S. (1984) Optimization Theory and Applications, Wiley Eastern Ltd., New Delhi.

18. ROSKILL - RAW MATERIALS GROUP (1995) Gold. Market Update, Analysis and Outlook, Roskill Information Services, London.

19. RUDAWSKY, O. (1986) Mineral Economics. Development and Management of Natural Resources, Elsevier, Amsterdam.

20. SALANT, S.W. (1995) "The Economics of Natural Resource Extraction: A Primer for Development Economists", The World Bank Research Observer, 10(1): 93-111.

21. SCOTT, A.T. (1967) "The Theory of the Mine under Conditions of Certainty", in M. Godfrey (Ed.), Extractive Resources and Taxation, University of Wisconsin Press, Madison: 25-62.

22. SENGUPTA, J.K. (1982) Decisions Models in Stochastic Programming, North Holland, Amsterdam. 
23. SIEBERT, H. (1983) Ökonomische Theorie natürlicher Ressourcen, Mohr Verlag, Tübingen.

24. SWEENEY, J.L. (1993) "Economics of Depletable Resources: Market Forces and Intertemporal Bias", in G. Heal (Ed.), The Economics of Exhaustible Resources, E. Elgar, Aldershot: 191-207.

25. VOGELY, W.A. (1982) "Issues in Mineral Supply Modeling", in R. Amit and M. Avriel (Eds.), Perspectives on Resource Policy Modeling: Energy and Minerals, Ballinger, Cambridge Mass: 249-76.

26. VOGELY, W.A. (Ed.) (1985) Economics of the Mineral Industries, S.W. Mudd Series, American Institute of Mining, Metallurgical and Petroleum Engineers, New York. 